\title{
Beach replenishment: sea defences and a review of the role of artificial beach replenishment
}

\author{
D. E. NEWMAN
}

\section{Mr J. Duvivier, Lewis and Duvivier}

The massive reclamation or replenishment of eroding beaches with sand dredged from the sea bed as an alternative to sea walls, breastworks or other conventional forms of sea defence is an attractive concept, and the Author is to be congratulated on bringing it forward for discussion. Whether it can be much cheaper and just as effective, as claimed, must surely depend upon the circumstances of each individual case: for example the depth, slope and composition of the sea bed and foreshore, the tidal range, degree of exposure to rough seas, the configuration of the coast line, littoral drift and last, but not by any means least, upon the administrative set-up and facilities for carrying out, maintaining and financing a major scheme of this type

60. To a generation of engineers and contractors who can build Europoort and the Dutch delta scheme and is prepared to carry out the Maplin project and enclose large areas of the Wash or Morecambe Bay (if it is allowed and paid to do so), there should be no special difficulty in dredging 1, 2 or 3 million $\mathrm{m}^{3}$ of fine granular material from the sea bed and pumping it ashore. What is difficult to estimate to a consistent and acceptable degree of accuracy is how much it will cost to pump the necessary amount of sand ashore in the first place ( $I$ assume the Author's claims relate exclusively to sand as I can find no reference to replenishment with gravel from off-shore deposits), and, what is probably even more difficult, to predict what will subsequently happen to the reclamation under normal average weather conditions year in and year out.

61. The Author accepts that on some coasts the provision of groynes may be helpful, even necessary $(\$ 18)$, and the bulk of his criticism is directed against sea walls and in particular steep walls, which are said to cause loss of material from the beach ( $\$ 2$ and 10) due to turbulence caused by wave reflexion from the wall.

62. I think, however, that it is unusual to build steep or vertical 'gravity' walls on beaches composed of soft, loose and erodible material. Such walls are normally found on coasts where the strata are relatively hard, e.g. Sunderland, Seaham, Sheringham, Cromer, Dover, Peacehaven, Brighton, Hove, Exmouth, etc., and provision is made by groyning the foreshore and, if necessary, by importing shingle from an outside source to protect the foundations and lower tidal levels of the walls against sea action. On soft, loose, erodible foreshores it is customary to spread the load over as wide an area as possible by means of sloping aprons or stepped foundations surmounted by relatively low curved superstructures backed by wide deckings and flood walls.

63. The Author reinforces the opinions expressed in the Paper by referring to 25 schemes which have been carried out at home and abroad during the last 25 years, and

Paper published: Proc. Instn Civ. Engrs, Part 1, 1976, 60, Aug., 445-460. 
makes special reference to Bournemouth and Portobello where the cost of restoring the beach by dredging and reclamation is said to have been less than the cost of capital works to protect the equivalent lengths of frontage. Figs 6 and 7 show that the beach between Bournemouth and Boscombe Piers was about $2 \mathrm{~m}$ below the promenade in 1968 and level with it in 1974. It was still level with the promenade when I visjted Bournemouth in August 1976, and if this is a direct result of the massive beach-feeding operations described by the Author and not a seasonal accretion due to the weather, it is a significant achievement.

64. Incidentally Fig. 6, taken in 1968 before sand replenishment was begun, shows what is unmistakably a sloping revetment type of sea wall backed by a promenade and floodwall, and it seems to me that what was carried out at Bournemouth between 1970 and 1975 could more accurately be described as a scheme of improvement of an existing defence rather than a coast protection scheme in its own right.

65. I would like to ask the Author to enlarge on the opinions expressed in the Paper on the subject of beach stability under the heading of 'rate of loss'. As sand of a medium grain size of $0.2 \mathrm{~mm}$, i.e. common wind blown beach or dune sand found between high and low water levels the world over, is an unstable material when exposed to waves, winds and currents, I would be reluctant to advise a local authority to involve the ratepayers and the sponsoring Ministry in an expenditure of $£ 1$ million or more on a new and relatively untried method of coast protection without further research.

66. There is a reference in $\S 8$ to a scheme for the artificial filling of $330 \mathrm{~m}$ of beach at Teignmouth which, it is said, if carried out would have been cheaper than carrying out repairs to the sea wall. I would hesitate at any exposed site to advise the authority to abandon an old sea wall, which can normally be repaired and reinforced by underpinning and encasement for a relatively small sum, in favour of a beach replenishment scheme. I would like to hear from the Author which particular part of Teignmouth sea front his remarks apply to, the quantity of reclamation or replenishment carried out, and whether the redeposited beach material has remained where it was placed.

67. I await with interest comments from the dredging fraternity on the Author's conclusions in $\$ 54-56$ on the experience the firms concerned have gained from the work already performed in the UK. The remarks under the heading 'Inclement weather' (§51) have a sinister ring.

Mr T. S. Hedges, Dept. of Civil Engineering, University of Liverpool

The Author has presented an interesting review of many of the factors to be considered when planning beach replenishment schemes. This contribution is aimed at highlighting a further factor which might be taken into account when selecting the borrow material.

69. In the Author's list of guidelines ( $\$ 57)$ he suggests that replenishment of the beach should be made with material having a $D_{50}$ size at least $1 \frac{1}{2}$ times that of the native beach sand. In general, this will provide a new beach which is steeper than the original, since there is a strong correlation between foreshore slope and median grain diameter for beaches subject to similar degrees of exposure to wave action. ${ }^{8}$

70. King ${ }^{9}$ has suggested that the decrease in beach slope with decreasing grain size results from the reduction of the percolation rate through the beach material. In a very permeable shingle beach a large proportion of the advancing wave swash sinks into the beach, and consequently there is a reduced backwash volume. On a fine sand beach only a relatively small volume of swash is lost by percolation owing to the much lower permeability. The importance of the backwash volume has been clearly shown in model tests. ${ }^{10}$ Even on slopes as flat as those suggested by the Author for initial grading of borrow material $(1: 15$ to $1: 25)$ the volume of the backwash has a large influence on the seaward water particle velocities beneath the advancing breakers, the seaward velocities reducing as backwash is reduced. In addition, permeability has been shown to have a marked effect on the wave-induced pressure gradients in the sea bed. ${ }^{11}$ These pressure gradients may produce momentary failure of the bed material, causing it to be set in motion. ${ }^{12}$ 


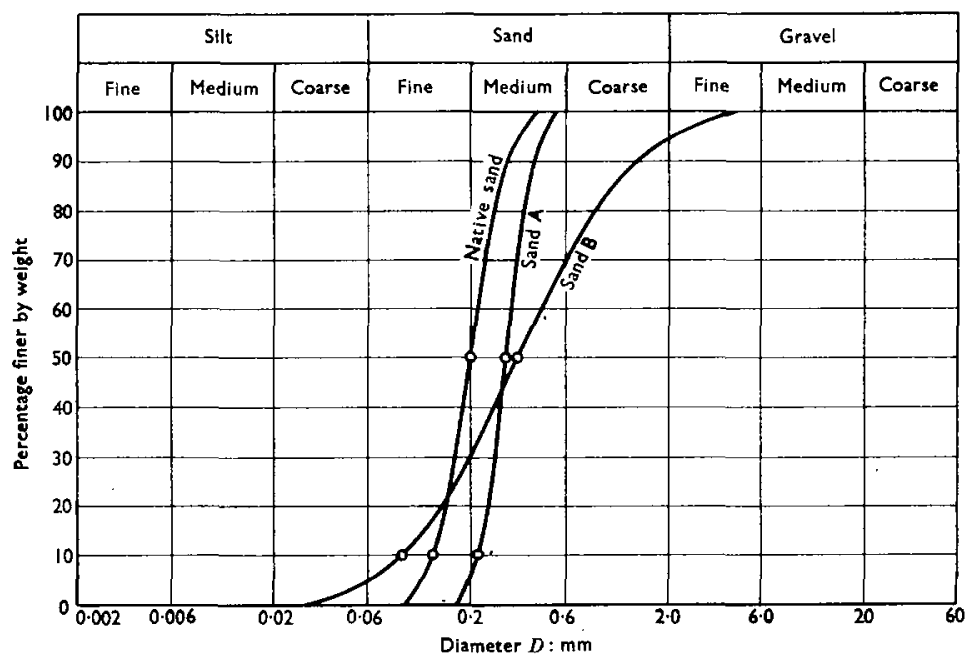

Fig. 8. Grain size distribution of native and borrow sands

71. Whilst it might be expected that, in general, the permeability of sands will increase as the $D_{50}$ size increases, the finer grains are much more important in determining permeability. Loudon (following Hazen) has shown that for many sands permeability is roughly proportional to the square of the $D_{10}$ size. ${ }^{13}$ Consequently, it may be advisable to consider the effects of differences in $D_{10}$ grain size as well as in $D_{50}$ size when comparing possible sources of borrow material.

72. Figure 8 shows the grain size distributions of a native beach sand and of two other sands available for replenishing the beach. Sands $A$ and $B$ both have $D_{50}$ grain sizes at least $1 \frac{1}{2}$ times that of the indigenous material, and since B's is the greater this sand might seem at first to be the more suitable. However, the permeability of sand $B$ is likely to be less than that of the native material (using the $D_{10}$ criterion) and so if it is used for replenishment the extra stability (and resulting steeper slope) produced by its generally coarser grains may be partially offset by the effects of the poorer permeability. In addition, the sorting action of the sea would almost certainly remove those grains finer than the native sand's. This action would improve the permeability, of course, but this would be at the expense of significant loss of material. On the other hand, sand $A$ is likely to be more permeable than the indigenous sand (which should add to its stability) and would be unlikely to suffer greater losses.

\section{Mr J. A. Lewis, Lewis and Duvivier}

The Author has provided an interesting and useful compendium of information on beach replenishment with sand. Similar information on the use of shingle would be valuable.

74. The Hydraulics Research Station was concerned with tracer experiments at Aldeburgh which preceded a very large scale beach replenishment scheme comprising the return from the downdrift end of the beach south of Orford Ness of a very large quantity of shingle. The scheme included the construction of new groynes in front of the sea wall and appears to have been highly successful. Further information about this scheme could be interesting.

75. My firm carried out its first beach replenishment scheme at Herne Bay in 1951 with approximately $765 \mathrm{~m}^{3}$ of shingle brought back from the large accumulation on the 
east side of Hampton Pier and placed on a short length between groynes opposite the Clock Tower in the centre of the town. Monitoring of such a small quantity could not be very accurate but sections taken a few years later showed that the beach had still benefited. More substantial beach nourishment has been carried out here recently by the local authority. A similar small replenishment of the beach on the west side of the disintegrator station below the east cliff was carried out in 1963.

76. Since then larger schemes have been carried out at a number of places (Table 3 ). In all cases the material was deposited between new or existing groynes. At Herne Bay a mixture of as dug ballast and rejects was used as providing a suitable and economical mixture.

77. A scheme was discussed with the Kent River Board in 1970 for very large scale beach replenishment, but it appeared to be more costly than continuing to maintain the defences with a modest beach, as at present. Also the cost of maintenance was very difficult to estimate with the degree of certainty which would be required by any local authority. A further complication was that a full beach would build up to approximately $5 \mathrm{~m}$ OD and the sea walls vary in level from $+3.9 \mathrm{~m}$ to $+4.9 \mathrm{~m}$.

78. At Dovercourt dredged ballast was landed in Harwich and transported by road to the site. The material for Lyme Regis was partly ballast with a high proportion of sand dug from the harbour and partly dug ballast from a pit. At Abersoch the material was mainly sand, but also included some small shingle and was taken from accreting areas. A quantity of beach cobbles found behind the line of the wall was also excavated and put on the beach. At Barmouth crushed granite was used. The sharp edges were objected to at first, but they had worn reasonably smooth within a year. At the other sites beach material was returned from downdrift areas of accretion, but at Aberaeron stony material washed down by the river and dug out of the harbour was also used.

79. All the schemes can be seen by visual inspection to have been successful in varying degrees. Unfortunately no accurate monitoring has been carried out.

Mr M. G. Barrett, Lewis and Duvivier

The Author is to be complimented on this Paper, which deals with an important aspect of coast protection work and gives interesting examples of large beach nourishment

Table 3

\begin{tabular}{l|c|c}
\hline \multicolumn{1}{c|}{ Location } & Date & $\begin{array}{c}\text { Approx. replacement } \\
\text { volume, } \mathrm{m}^{3}\end{array}$ \\
\hline Herne Bay: east cliff at foot of Beacon & & \\
Hill & 1970 & 6000 \\
Hampton Pier Avenue & 1973 & 1500 \\
Harwich-Dovercourt & $1971-74$ & 33300 \\
Brightlingsea & $1962-63$ & 2300 \\
Frinton Park Estate & $1967-68$ & 3600 \\
Frinton Cliffis & 1965 & 2500 \\
Lyme Regis east cliff & 1966 & 2750 (sand) \\
Amroth & 1968 & 12500 \\
Abersoch & 1968 & 5000 \\
$\quad$ ", & 1968 & 3800 \\
Barmouth & 1972 & 3800 (sand and fine shingle) \\
Aberaeron & 1972 & 1500 (sand) \\
Cei Bach & 1972 & 600 (cobbles) \\
& 1974 & 1600 \\
\hline
\end{tabular}


schemes. The title of the Paper suggests a general review of the subject of artificial beach replenishment for coast protection. I assume however from the examples given in the Paper, particularly Table 2, that it was the Author's intention to limit his review mainly to the use of sand.

81. While the use of sand has clear advantages over coarser materials so far as amenity is concerned, it has distinct limitations with regard to wave climate and tidal range. Volume for volume, gravel or shingle provides a far more effective and stable protection in those locations where it is environmentally acceptable, and it can subsequently be more easily controlled. For this reason artificial nourishment with coarser material is much more frequently used in the UK as a coast protection expedient than sand. The Author might care to enlarge the scope of Table 2 to include such schemes and to illustrate the extent to which artificial nourishment is already used in Britain.

82. One of the problems of artificial nourishment particularly in exposed locations with a high rate of littoral drift, is the extent and uncertainty of future recharge requirements. Can the Author give details of the losses incurred to date on the two major UK schemes which he describes?

83. Local authorities which are Coast Protection Authorities can obtain grant aid under the Coast Protection Act 1949 towards capital coast protection works, but maintenance costs are not normally grant aided. While initial artificial beach replenishment schemes have been considered for grant aid in association with capital works, it appears that subsequent recharge of beaches to maintain levels is currently considered as maintenance. There is therefore a natural reluctance by local authorities to adopt schemes which will involve them in a rather uncertain and probably high level of future expenditure on maintenance as opposed to capital works. Added to this there is also an understandable prejudice among many local councillors to spending public money on beach material rather than on, to them, some more apparently stable and permanent structure.

84. Artificial nourishment with gravel from either inland quarries or sea-dredged sources is frequently used to supplement particular local deficiencies in the natural supply. Examples of locations where this expedient has been adopted include Warden Bay in the Isle of Sheppey, Wittering, Aldwick, Felpham and Middleton-on-Sea in Sussex, and Yarmouth and Totland Bay in the Isle of Wight.

85. The term artificial beach nourishment should, I suggest, also include the process of recycling and transfer of shingle from one area of beach to another, reversing the natural process of littoral drift. This method has been used extensively in various parts of the UK. Examples include Borth in Ceredigion and Selsey in Sussex, and indeed also the operation at Teignmouth quoted by the Author in $\S 8$.

86. The Author is also acquainted with the beach nourishment operation at Aberystwyth where, in the absence of any suitable local source of gravel, quarried stone has been used in a series of operations starting in 1961 and involving a total of over $27000 \mathrm{~m}^{3}$ to date. Losses at this very exposed site are mainly due to abrasion and attrition of the natural beach material.

Messrs P. Wright and N. B. Webber, Dept of Civil Engineering, University of Southampton

This is an informative and timely paper on a concept that is relatively new to the British Isles, although practised for many years, as Table 2 shows, in the USA.

88. In $\S 57$ the recommendation is made that the $D_{50}$ size of the introduced sand should be at least $50 \%$ coarser than that of the indigenous material. Although in the case of Bournemouth a convenient offshore borrow area satisfying the criterion was found, these favourable circumstances may by no means always prevail, since there is a tendency for the material grading to become finer as one proceeds further offshore. A difficult problem would then be posed of balancing a more costly haul against a potentially more rapid rate of loss of material. 


\section{DISCUSSION}

89. If the guideline is extended to include material of shingle size-and it is appreciated that the Paper is concerned almost exclusively with sand-then some caution is needed, particularly if conditions are conducive to significant longshore drift and the beach to be nourished is only partially denuded and is located in a unit of coastline that exhibits in plan a sorting of sediment by size. The last is, incidentally a common feature of log spiral bays, such as Christchurch Bay.

90. Groynes would obviously serve to restrict artificially the longshore drift, but it is conceivable that, with time, considerable quantities of the fill material could be transported to an adjacent part of the coastline where its grain size would match that of the material found naturally on the beach.

91. In the circumstances described, the nourishment of a beach with shingle of similar rather than greater dimensions might be considered a better solution. The important point to be emphasized is that in planning a replenishment operation one should consider not only the beach to be nourished but also the entire unit of coastline in which it is situated.

\section{Mr A. E. Marsden, Anglian Water Authority}

The Author is to be congratulated on the excellence of his Paper on this interesting subject.

93. Consideration of certain principles may help to reduce the amount of loss from in front of new sea walls. The top level of toe piling to the wall should not normally be significantly above lowest beach levels, rated over a number of years, and the slope of the apron or stepwork should be as fiat as possible, consistent with reasonable costs, and in any case not steeper than about 1 to $3 \frac{1}{2}$. In most works involving the construction of new walls and groynes it is often provident to allow for some nourishment of the beach on a provisional basis between completed groynes.

94. Nourishment of beach need not necessarily be with sand, although this obviously has an amenity value, or from offshore sources. In the mid-1960s one beach in East Anglia was 'fed' by material from a large accretion of gravel from the downdrift side. The quantity of material, moved by light railway, was some $350000 \mathrm{~m}^{3}$.

95. I consider it is an oversimplification to compare the cost of a beach replenishment scheme with that of a sea wall. To make a fair comparison one must ascribe a 'life' to each solution so that discounting may be done over an appropriate period. In such a study future costs would be assessed to complete the picture. It should be said, however, that nourishment with sand may represent a benefit which can be assessed in monetary terms in the case of a resort.

96. These opinions are my own personal ones and do not necessarily reflect those of my employer.

\section{Mr D. E. Newman}

My intention was to cover those replenishment schemes involving large quantities of sand. Because many of the shingle renourishment schemes are relatively small, they seem to have attracted a minimum of monitoring and therefore do not form a good basis on which to make quantitative comparisons. However, $I$ am aware of a number of these schemes which in nearly all cases have provided some measure of success in achieving coast protection. Details of the shingle replacement at Sheerness, undertaken recently by the Southern Water Authority as a flood protection measure, came to me too late to be included in the Paper and it is too recent for any assessment of stability to have been made.

98. Though I am unable to comment on the way in which the costs of pumping material ashore are arrived at, I agree with Mr Duvivier on the difficulty of achieving a realistic estimate. Clearly, if a nourishment scheme is based on a complete refill every 10 years, a direct comparison with the costs of maintaining a sea wall may be possible. However, because many of the schemes examined in the Paper are relatively recent it 
has not been possible to establish a 'half life' for restored beaches. The 1 in 100 year storm that arrives during the week following renourishment is unlikely to provide the conditions that would promote this technique to the local authorities who, as $\mathbf{M r}$ Barrett suggests, would be more likely to invest their resources in capital works of apparently more stable and permanent nature.

99. In agreeing with Mr Duvivier that steep or vertical gravity walls are rarely built on soft, loose or erodible material, there are, nevertheless examples of older work of this type still to be found in some resorts. Mr Marsden considers that any revetment

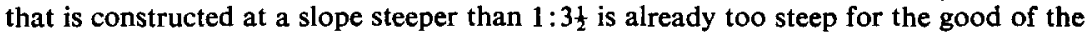
beach, but parts of Exmouth and Bournemouth walls fall into this category. Even at Teignmouth the wall is nearly vertical.

100. The high beach at Bournemouth, visited by Mr Duvivier in August 1976, is purely a result of artificial beach building. Between the piers the sea has not reached the wall since before July 1974 . About $260000 \mathrm{~m}^{3}$ of sand were pumped ashore over this section and to date the seasonal fuctuation is of the order of $50000 \mathrm{~m}^{3}$, summer to winter (Fig. 9). As the scheme has been monitored for just over 2 years it is still too early to forecast the seasonal changes in say 10 years' time. It is clear, however, that the summer-winter changes at the eastern end of the frontage (which is more exposed to wave action) are double those between the piers and represent changes of about $50 \%$ of the volume of the material placed there artificially.

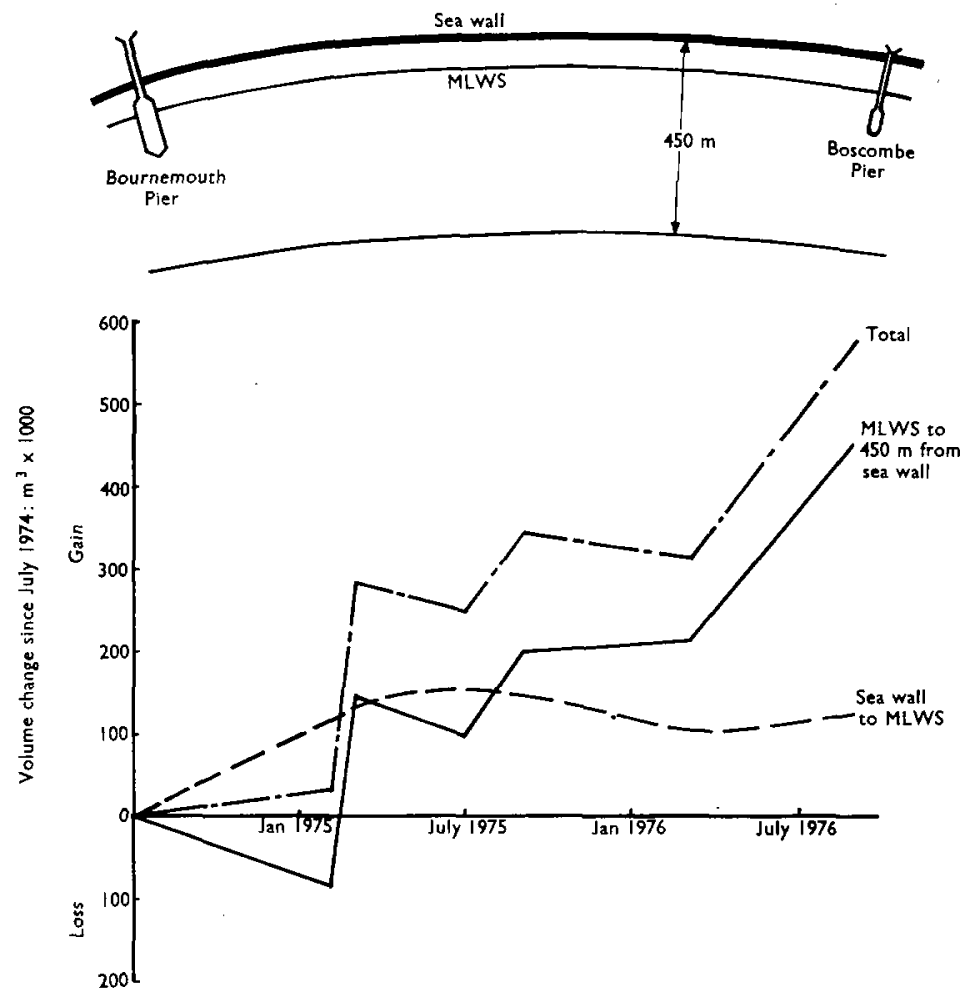

Fig. 9. Variation in volume with time: Bournemouth Pier to Boscombe Pier 
101. If the Bournemouth scheme is considered merely as an improvement to an existing coast protection scheme, as $\mathrm{Mr}$ Duvivier suggests, I can only comment that as the sea has not yet reached the wall between the piers, the wall can play no part in the stability or otherwise of the beach, and that at least until the present time conditions would have been just the same if the wall had not been there.

102. The only case of renourishment with fine sand $(0.2 \mathrm{~mm})$ that $I$ reviewed in the Paper was that of the Island of Goeree in the Netherlands. This may be regarded as a very special case and the placement of vast quantities of sand on the beach at this site was an effort to prevent the land from flooding by using the only material available. It is clear from Table 1 that the rate of loss of this fine sand during the pumping operation was far higher than would be acceptable on most contracts, and I agree that sand of this size contributes very little to the stability of any beach on a long term basis.

103. The $330 \mathrm{~m}$ of frontage at Teignmouth, groyned and replenished with coarse sand and referred to in $\S 8$, is that portion of the beach immediately to the south of the pier. It is understood that the material was taken from other parts of the beach and mostly from a coarse sand bar close offshore. About $30000 \mathrm{~m}^{3}$ of sand were placed between four new groynes and graded back to the sea wall. . Not only has this material remained in position, but in November 1976 it was reported that the groynes were fully covered with material.

104. This area of beach is not typical of most inter-tidal areas. A complex circulation of bars of coarse material in the entrance to the Teign river gives rise to intermittent contributions of material to the beach whenever the offshore bars are driven ashore. Usually this occurs in the area of the new groynes, which have the effect of trapping such material and building up the beach.

105. Mr Hedges has a sound approach in his understanding of grain size and beach slopes and the effect of permeability. Permeability varies with the density and viscosity of the water, the degree of turbulence, the porosity of the sand and the shape and arrangements of particles. (It can be seen, therefore, that as the porosity increases so must the permeability.) The porosity is dependent on the grain size and the grading of the sand.

106. Hazen's relationship between permeability $k$ and the $\mathrm{D}_{10}$ size $\left(k \propto \mathrm{D}_{10}{ }^{2}\right)$ was derived empirically from filter sands, but makes no allowance for variation in porosity or in the shape of particles.

107. It would be interesting to know from the various schemes that have taken place just how the 'placed' fines have been lost. Unfortunately the costs of analysis and monitoring are too high for most authorities to include such work in their budgets.

108. One would expect that $20 \%$ of sand ' $B$ ' as shown in Fig. 8 would disappear rapidly if this sand was used for nourishment on most beaches. Normally the contractor would take such inevitable losses into account when estimating for the work.

109. The immediate loss of bulk on those contracts that have been accompanied by some degree of monitoring appears to be of the order of $20-30 \%$. Nevertheless, an offshore source of material near to hand but likely to be only $80 \%$ of use as a replenishing medium may be cheaper than a longer haul to obtain something better.

110. Mr Lewis mentions that within 1 year the sharp edges of crushed granite used to nourish the shoreline at Barmouth had worn reasonably smooth. This is a particularly interesting piece of information in view of the apparent reluctance of some authorities to use quarried sources of material. Clearly the degree of abrasion of such materials would depend on the nature of the site.

111. Monitoring of beach processes is expensive. Any attempt to discover the relationship between movement and wave height, period and direction is, in itself, a costly exercise. The effect of storms can only be recorded if both hydrographic and topographic surveying can be carried out at short notice and the offshore portion only if weather permits. The relationships between the various parameters obtained in test tanks do not, unfortunately, provide a true degree of comparison in nature, though the general behaviour of a beach can be more easily understood by the model study. 
112. An extension of Table 2, as suggested by Mr Barrett, to include some details of beach nourishment with shingle, could almost be the subject of a separate paper. The collection of data for this purpose is time consuming, but I would agree that it might be worthwhile and help to bring the subject up to date.

113. Both the Portobello and Bournemouth schemes are continuously monitored for beach loss by the Hydraulics Research Station. At Portobello the data is supplied by the Lothian Regional Council and at Bournemouth by the Borough Council. The latter receives financial aid from the Department of the Environment for this purpose.

114. At Portobello, about $180000 \mathrm{~m}^{3}$ of sand were pumped ashore in 1972. This was graded to a slope of about 1:20 and six groynes were built, spaced equidistantly over the $1.6 \mathrm{~km}$ frontage. Thereafter the beach has been surveyed at least once annually over 30 sections stretching from the sea wall to $100 \mathrm{~m}$ seawards. These profiles do not cover the renourished area completely, but give sufficient information on the stability of the upper beach. Table 4 shows the state of the beach from 1972 to March 1976.

115. At Bournemouth, where the eastern end of the frontage is generally more exposed than Portobello, the initial losses have, as anticipated, been higher. In the relatively short time since the operation was completed it is difficult to make a sensible assessment, but the following figures are given for what they are worth. In 1974-5, $650000 \mathrm{~m}^{3}$ of sand were pumped ashore. In September 1975 the beach volume was calculated from 34 cross sections to be in credit over the prenourishment volume by $660000 \mathrm{~m}^{3}$. The following spring this new volume had been reduced to $320000 \mathrm{~m}^{3}$, or about half of the volume contributed by artificial fill. In September 1976, the latest figures available show an increase to $380000 \mathrm{~m}^{3}$ above the prenourishment level. On the figures available it would be unwise to quantify the likely summer-winter loss at this stage. The above results refer to the intertidal area only. There has been a considerable increase in the volume of material just offshore and there is no reason to believe at this stage that the system as a whole has lost material. Clearly the inshoreoffshore or summer-winter interchange is an important factor.

116. It is worth noting that the groyne system at Bournemouth had not been completed before the pumping operation finished and some sand was inevitably lost. In particular, it would have been advantageous to have constructed the terminal groyne at the eastern end of the frontage well in advance of the pumping operation. Unhappily this was delayed for financial reasons.

117. Mr Barrett points out $(\$ 83)$ that there may be a natural reluctance on the part of local authorities to adopt schemes of a rather uncertain and probably high level of future expenditure and maintenance as opposed to capital works. I am sure that he is correct in his thoughts, but hope that experience gained on the results of existing schemes will do much to alleviate the reluctance to go in for a relatively new but infinitely more attractive method of coast protection wherever it appears to be feasible.

118. Messrs Wright and Webber raise the question of the size of shingle $(\$ 91)$ required for nourishment and suggest that this should match that already on the beach.

119. The object of nourishment is to replace material which has been lost due to natural or other causes. In the case of material taken manually from the littoral

Table 4

\begin{tabular}{l|c}
\hline \multicolumn{1}{c|}{ Year } & Volume increase after May 1972, $\mathrm{m}^{3}$ \\
\hline 1972 & $+180 \cdot 000$ (pumped) \\
1973 & $145 \cdot 000$ (remaining) \\
1974 & $145 \cdot 500 \quad "$ \\
1975 & $155 \cdot 230 \quad$, \\
1976 (Jan.) & $152 \cdot 320 \quad$, \\
1976 (Mar.) & $153 \cdot 540 \quad$, \\
\hline
\end{tabular}




\section{DISCUSSION}

system, replacement of material of a similar size to restore the regime may be adequate. However, in an area of active erosion, the placement of material of the same size as that indigenous to the site would not stop erosion-and a high degree of maintenance would be expected. The Island of Goeree (\$31-33) is an example of this type.

120. Mr Marsden raises the question of comparing the 'lives' of sea walls with beach renourishment schemes. I would agree that this is difficult and that as methods of coast protection such an assessment is very important. On the amenity side, the advantages to be gained by the beach scheme in terms of deck-chair hire and other recreational facilities is also difficult to quantify.

\section{References}

8. WIEGEL R. L. Oceanographical engineering. Prentice-Hall, New Jersey, 1964, 358-359.

9. KnNG C. A. M. Beaches and coasts. Arnold, London, 1972, 324-325.

10. KEMP P. H. Wave asymmetry in the nearshore zone and breaker area. In Nearshore sediment dynamics and sedimentation, ed. J. Hails and A. Carr. Wiley, London, 1975, 47-67.

11. Moshagen $H$. and Tørum A. Wave induced pressures in permeable seabeds. J. Wat. Harb. ASCE, 1975, 101, WW1, Feb. 1975, $49-57$.

12. Madsen O.S. Stability of a sand bed under breaking waves. Proc. 14th Coastal Engineering Conference, Copenhagen, June 1974, 776-794

13. Louden A. G. The computation of permeability from simple soil tests. Géotechnique, 3, 1952-53, 165-183. 